\title{
When to Leave Carrots for Sticks: On the Evolution of Sanctioning Institutions in Open Communities*
}

\author{
Marina Chugunova ${ }^{\dagger} \quad$ Wolfgang J. Luhan ${ }^{\ddagger}$ \\ Andreas Nicklisch ${ }^{\S}$
}

April 22, 2020

\begin{abstract}
When asked, people dislike punishment institutions, although punishment is more effective than rewards to maintain cooperation in social dilemmas. Which institution do they choose in the long run? We study migration patterns in a laboratory experiment that allows participants to migrate continuously between punishment and reward communities. The majority of participants initially chooses the reward institution, but a substantial number of subjects joins the less profitable punishment community subsequently. In this case, the mere threat of punishment establishes high contributions. Income differences and missing compensations for cooperators in the reward community are the key factors for the decision to migrate.
\end{abstract}

Keywords: open communities; voting with feet; cooperation; sanctions; public goods

JEL-Classification: C72, C92, H41

*We thank Özgür Gürerk for providing detailed information on their experiment, Bernd Irlenbusch, Bettina Rockenbach, Marie Claire Villeval, participants of the 2016 ESA World Meeting, the $10^{\text {th }}$ RGS Doctoral Conference, seminar participants at the Ruhr-University Bochum, and the University of Portsmouth for helpful comments. We thank the editor and an anonymous referee for their valuable input. Financial support by the German Research Foundation (Ni 1610/1-1) and the Swiss National Science Foundation (100019E_178317/1) for Nicklisch is gratefully acknowledged.

${ }^{\dagger}$ Corresponding author: Max Planck Institute for Innovation and Competition, Marstallpl. 1, 80539, Munich, Germany; e-mail: marina.chugunova@ip.mpg.de

${ }^{\ddagger}$ Economics and Finance Subject Group Faculty of Business and Law, University of Portsmouth, Richmond Building, Portland Street, Portsmouth, Hampshire PO1 3DE, United Kingdom; e-mail: wolfgang.luhan@port.ac.uk

$\S$ Center for Economic Policy Research, University of Applied Sciences of the Grisons, Chur, Switzerland, Comercialstrasse 22, 7004, Chur, Switzerland; and SNF/DFG Research Group "Need-Based Justice and Distribution Procedures" (FOR 2104); e-mail: Andreas.Nicklisch@fhgr.ch 


\section{Introduction}

Among the multiplicity of means available to promote pro-social behavior in social dilemmas, research has shown that (peer) punishment is particularly suited to foster cooperation (e.g., Fehr and Gächter, 2000, 2002; Gächter et al., 2008). Indeed, a majority of social dilemmas feature some sort of punishment institutions (see, e.g., Gardner et al., 1990). Yet, this observation is puzzling in itself. If asked for their preference, people mostly do not opt for a punishment regime, but for the complete opposite - a reward system that allows them to approve cooperative behavior (Gürerk et al., 2014; Sutter et al., 2010).

This raises the question what conditions allow people to realize the benefits of punishment - if they do at all? To study this question, we analyze how peer-punishment and peer-reward institutions evolve in direct competition with each other in a dynamic setting. For this, we extend the analysis of Gürerk et al. (2014) by directly comparing reward and punishment communities. Studying this type of migration flows and institutional competition seems to be of particular political and academic importance in times of increasing mobility.

Our findings demonstrate the importance of income inequality for the rise and fall of the institutional regimes. People start discovering the benefits of another institution if their current institution substantially harms their fairness sentiments. Participants who are not rewarded for high contributions migrate subsequently to the punishment community - although the punishment community is less profitable than the reward community. Moreover, our results show that the existence of the unfair rewarding system remedies the welfare loss of the punishment system: having migrated from a reward community, less punishment is required to keep the levels of cooperation up. Hence, punishment systems under competition are less detrimental for welfare than if considered in isolation (see, e.g., Gächter et al., 2017).

\section{Design}

We follow the literature that explores the effectiveness of either punishment in comparison to rewards or a combination of both mechanisms for solving social dilemmas (Andreoni et al., 2003; Sefton et al., 2007; Rockenbach and Milinski, 2006; Rand et al., 2009; Hauert, 2010; Hilbe and Sigmund, 2010; Milinski and Rockenbach, 2012). To facilitate the comparison of our results, we implemented a design that is - in the basic structure and the parameterization - similar to Gürerk et al. $(2006,2014)$. The experiment consists of three stages: (i) community selection, (ii) public goods game and (iii) sanctioning, which are repeated for 30 periods. We use 12-people matching groups who interact anonymously.

Community selection: We analyze two treatment conditions. In PR players choose between two communities: one with a punishment system and another with a reward system. In PN players choose between a community with a punishment system and a community without any sanctioning system. In each treatment, players only interact within their chosen communities. ${ }^{1}$

\footnotetext{
${ }^{1}$ Instructions in the Appendix. The analysis of other combinations of institutional regimes, e.g., RN, can be found in Gürerk et al. (2014).
} 
Public goods game: After choosing the community, each player receives an endowment of 20 tokens. Tokens that are contributed to the public good are multiplied by 1.6 and are split equally among all members of the group. ${ }^{2}$

Sanctioning: When all members of the community have made their contribution decision, they proceed to the sanctioning stage. Each player receives an additional endowment of 20 tokens as well as feedback on individual contributions of the other community members. ${ }^{3}$ In the punishment (reward) system players may assign points to other community members reducing their own income by one and reducing (increasing) the income of targeted community members by 3 tokens. ${ }^{4}$ The sanctioning decisions in both regimes are taken simultaneously by all players. Due to changing player IDs, our design does not allow for reputation building. Therefore immediate action is required if sanctions are to be imposed.

After sanctioning, players receive feedback on their individual performance in the current period and the average performance for the past behavior in both communities, including the contribution, the income after the public good game, received and distributed points - if applicable - and the total payoffs.

We conducted 7 sessions of roughly 2 hours each with 156 participants in total at the WISO Research Laboratory at the University of Hamburg using z-tree (Fischbacher, 2007) and hroot (Bock et al., 2014). Participants were granted a starting endowment of 10 Euro. Mean payoffs were 25 Euro, raining from 19.10 to 32.60 .

\subsection{Hypotheses}

The focus of our study lies on the migration between institutions, its causes and the evolutionary dynamics of the systems. Applying existing social preference models does not allow us to produce predictions for these questions. Therefore, we rely predominantly on previous empirical findings to formulate our hypotheses.

For PR, the existing literature (e.g., Sutter et al., 2010) suggests that participants favor the reward community.

$H_{1}$ :In the PR treatment the majority of participants initially joins the reward community.

Our second and main hypothesis relies on the earlier findings that the reward regime offers efficiency gains, but the high contributions are usually not sustainable in this regime (Andreoni et al., 2003; Sefton et al., 2007; Gürerk et al., 2014). This suggests that after initially joining the reward community in $\mathrm{PR}$, people migrate from the reward to the punishment community as soon as the rewards and subsequently the contributions decline in the rewards community.

$H_{2}$ : In the PR treatment participants gradually migrate from the rewards to

\footnotetext{
${ }^{2}$ If a community consist of only one member, the entire endowment is transferred to the private account.

${ }^{3}$ In a community with a single member or without sanctioning, players also receive an additional endowment.

${ }^{4}$ We test deliberately migration to the punishment regime under utmost favorable conditions for rewards: the potential benefits from only two players mutually rewarding each other (i.e., 60 tokens per player) outweigh almost twice the benefits from full cooperation of those two players in the public good game (i.e., 32 tokens per player).
} 


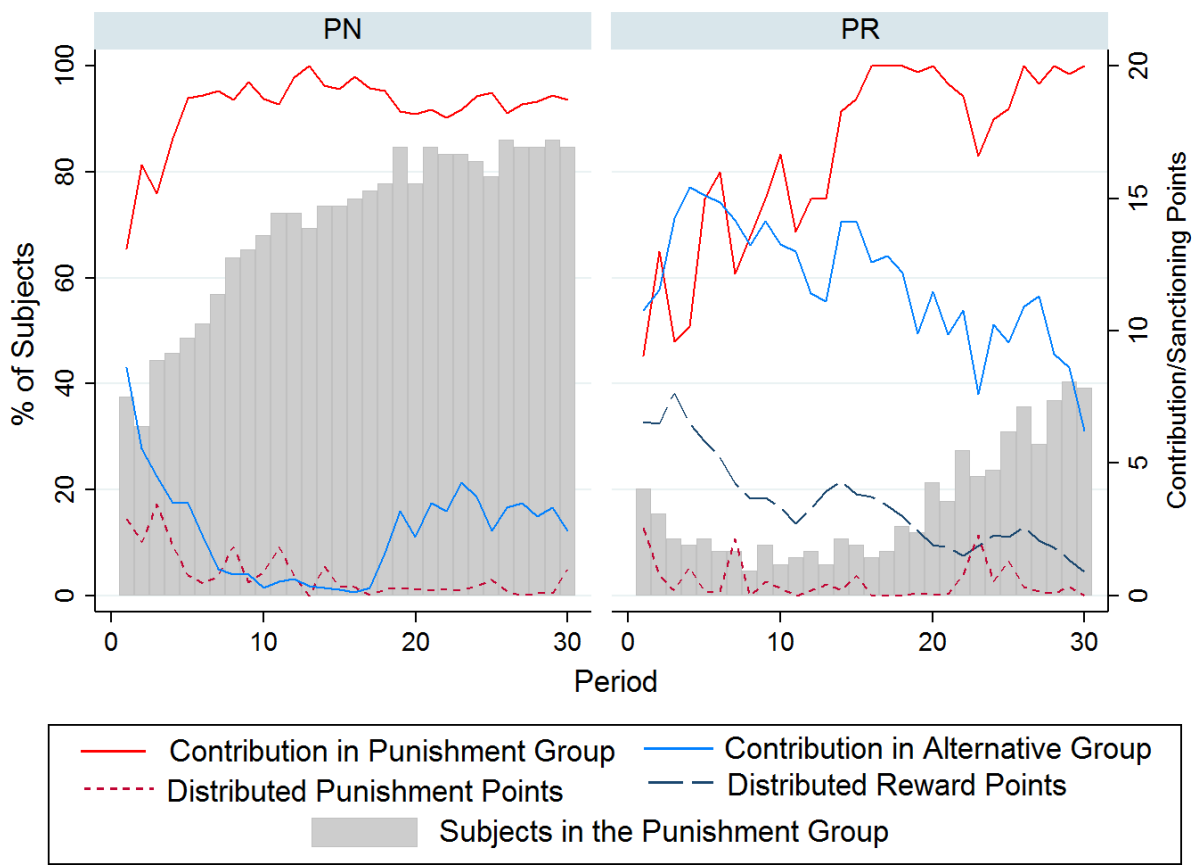

Figure 1: Community Choice, Contribution and the use of Points over Periods

the punishment community.

The crucial questions for our analysis is not only whether, but also why people will start exploring the alternative institution and eventually migrate to the punishment community. As full contributors suffer most from free-riders in malfunctioning reward communities, we expect them to initiate the migration to the punishment regime. Yet, it is a priori unclear which specific circumstances trigger this process.

\section{Results}

Supporting the results from the previous literature (Gürerk et al., 2014), the majority of participants choose the punishment community if given the option between punishment and no sanction. They achieve high levels of cooperation by using punishment in the initial periods while contributions in the nonpunishment community remain low throughout the experiment (see Figure 1, left panel).

The right panel of the graph, containing the $\mathrm{PR}$ treatment shows more variation over time: in the beginning, over $80 \%$ of the people choose the reward community, which gradually reaches the highest popularity around period 15 with about $90 \%$ of the population. A Jonckheere-Terpstra test confirms a trend reversal: until period 15 participants predominantly choose the reward group $(\mathrm{p}=0.0034)$, after this point the trend reverses with an increasing fraction choosing the punishment community $(\mathrm{p}=0.000)$. The data support our hypothesis $\mathrm{H}_{1}$ : people initially prefer the reward community. However, the trend reverses in 
line with our hypothesis $\mathrm{H}_{2}$ in the second half of the experiment; people start to migrate to the punishment community in increasing numbers. Thus our results demonstrate that some players change their initial preference for rewards over the course of the experiment. It is remarkable, however, that despite the significant migration trend towards the punishment regime, the reward community retains roughly $60 \%$ of participants even after 30 periods. $^{5}$

Those migration patterns may coincide with changes in the rates of contribution and profits of different communities. The level of contribution differs significantly between regimes, with the punishment community in the PN treatment condition ${ }^{6}$ performing best, with an average contribution of $17.4(\mathrm{p}=0.045$ if compared to $\mathrm{P}(\mathrm{PR})$ and $\mathrm{R}(\mathrm{PR}))^{7}$ This reconfirms that punishment seems to be better suited for sustaining a higher level of contribution. The reward community in our experiment achieves a relatively stable level of contribution at ca. $60 \%$ of the full endowment level (11.9), however, with a decreasing trend.

The profits in $\mathrm{R}(\mathrm{PR})$ and $\mathrm{P}(\mathrm{PR})$ communities are significantly different over all 30 , or only the first 15 periods (Wilcoxon signed-rank test $\mathrm{p}=0.018$ and $\mathrm{p}=0.03$ respectively). Despite the decrease in the second half, the $\mathrm{R}(\mathrm{PR})$ profits remain higher than those of $\mathrm{P}(\mathrm{PR})$, but the difference is not significant anymore $(\mathrm{p}=0.13)$. The higher profits in the reward community throughout the game do not stop migration toward the punishment regime.

Punishment points are used differently in $\mathrm{P}(\mathrm{PN})$ and $\mathrm{P}(\mathrm{PR})$ communities (see Fig. 1). In the first half of the experiment on average 10.7 points per group are distributed in $\mathrm{P}(\mathrm{PN})$ and only 4.5 in $\mathrm{P}(\mathrm{PR})$ group (Mann Whitney $\mathrm{U}$ test, $\mathrm{p}=0.006)$. In the second half of the experiment punishment points are rarely used in $\mathrm{P}(\mathrm{PN})$ (2.6), but the average use of punishment points per group goes up slightly in $\mathrm{P}(\mathrm{PR})(5.7, \mathrm{p}=0.11)$ (see Fig. A1 in the Appendix). The establishment of an effective punishment community in the PN treatment requires people to discipline each other in the first periods of the game only, relying on the threat of punishment later on to keep up contributions. In the punishment regime in the PR environment, however, the threat of punishment alone appears to be sufficient to promote cooperation from the very beginning, avoiding the welfare losses of punishment. This is remarkable, since there is gradual migration into $\mathrm{P}$ communities both in $\mathrm{PN}$ and $\mathrm{PR}$.

Unlike punishment in PR that can sustain high cooperation by the mere threat, reward regime requires actual rewarding of contributors in every period to ensure pro-social behavior in future periods: Reward points are indeed frequently assigned in the beginning of the game but the level is decreasing over time (Fig. 1). The existence of the reward community postpones the establishment of a flourishing punishment community, yet increases significantly the payoffs in the latter setting. Migration between the two sanctioning institutions leads to less inefficiencies than migration into the punishment regime from a sanction free environment.

For the evolution of a regime, the question of who uses a sanctioning mech-

\footnotetext{
${ }^{5}$ This is in line with Sutter et al. (2010) who observe a preference for the rewards regime even when a more effective punishment regime is available.

${ }^{6}$ Hereafter denoted as $\mathrm{P}(\mathrm{PN})$, other groups are denoted accordingly.

${ }^{7}$ For all further analysis only groups of 2 and more players were considered. p-values can be found in Table A1 and Table A2 in the Appendix. All non-parametric tests reported are two-tailed and take communities as units of observations; that is, tests are applied to the aggregated values for 6 independent observations in PN treatment and 7 in PR treatment.
} 
anism is as important as whether it is used at all. In $\mathrm{R}(\mathrm{PR})$ in the first half of the game free-riders and those who do not contribute fully generously reward full-contributors ${ }^{8}$. In the second half, the total use of points decreases and now it is mainly the contributors themselves, who keep rewarding others and have to bear the costs - while not getting any compensation from the free-riders. This development creates an unequal distribution of income, which in turn may cause migration towards the punishment community (see Figures A2 and A3 in the Appendix).

To determine if inequality within the community affects migration decision we run a random effects probit regression with the inequality measure (difference of income within community) calculated in the spirit of Bolton and Ockenfels (2000) and Jasso (2007). The regression results confirm that growing inequality within the $\mathrm{R}$ community is an important factor for a migration decision (see Table A4 in the Appendix).

\section{Conclusion}

Participants initially prefer reward institutions. Yet, over time a substantial number of participants migrate to a punishment institution. Surprisingly, the average payoffs play only a limited role in migration, but increasing inequalities in the rewards community and the absence of rewards for full contributors initiates the migration. Despite the significant migration trend from the reward to the punishment community, the former retains the majority of participants over 30 periods. Importantly, under direct competition between punishment and reward communities, the gradual inflow allows the punishment mechanism to sustain persistently high levels of cooperation by mere threat (rather than actual punishment). Thus, under competition sanctioning community avoids the initial stage of high punishment that is associated with high welfare losses. This result gains additional importance in the light of the recent findings of Gächter et al. (2017) that the welfare loss from punishment in the early periods grows exponentially and is potentially harmful.

Our findings highlight the importance of a factor which is easily overlooked in socio-economic research: the institutional frame of open societies reflects an ongoing institutional competition. Institutional regimes do not develop in isolation, they rise and fall as they compete with alternative arrangements. The gradual inflow of people from alternative settings assure the emergence of persistent solutions for dilemmas serving best the trade-off between our needs, both for efficiency and - equally important - for fairness.

${ }^{8} \mathrm{~A}$ similar pattern of was found in Sutter et al. (2010). 


\section{References}

Andreoni, James, William Harbaugh, and Lise Vesterlund (2003). "The Carrot or the Stick: Rewards, Punishments, and Cooperation". In: The American Economic Review 93.3, pp. 893-902.

Bock, Olaf, Ingmar Baetge, and Andreas Nicklisch (2014). "hroot: Hamburg registration and organization online tool". In: European Economic Review 71, pp. 117-120.

Bolton, Gary E and Axel Ockenfels (2000). "ERC: A theory of equity, reciprocity, and competition". In: The American Economic Review, pp. 166193.

Fehr, Ernst and Simon Gächter (2000). "Fairness and retaliation: The economics of reciprocity". In: The Journal of Economic Perspectives 14.3, pp. 159-181.

- (2002). "Altruistic punishment in humans". In: Nature 415.6868, pp. 137140.

Fischbacher, Urs (2007). "z-Tree: Zurich toolbox for ready-made economic experiments". In: Experimental Economics 10.2, pp. 171-178.

Gächter, Simon, Friederike Mengel, Elias Tsakas, and Alexander Vostroknutov (2017). "Growth and inequality in public good provision". In: Journal of Public Economics 150, pp. 1-13.

Gächter, Simon, Elke Renner, and Martin Sefton (2008). "The long-run benefits of punishment". In: Science 322.5907, pp. 1510-1510.

Gardner, Roy, Elinor Ostrom, and James M Walker (1990). "The nature of common-pool resource problems". In: Rationality and Society 2.3, pp. 335358.

Gürerk, Özgür, Bernd Irlenbusch, and Bettina Rockenbach (2006). "The competitive advantage of sanctioning institutions". In: Science 312.5770 , pp. 108111.

- (2014). "On cooperation in open communities". In: Journal of Public Economics 120 , pp. 220-230.

Hauert, Christoph (2010). "Replicator dynamics of reward \& reputation in public goods games". In: Journal of Theoretical Biology 267.1, pp. 22-28.

Hilbe, Christian and Karl Sigmund (2010). "Incentives and opportunism: from the carrot to the stick". In: Proceedings of the Royal Society of London B: Biological Sciences, rspb20100065.

Jasso, Guillermina (2007). "Studying justice: Measurement, estimation, and analysis of the actual reward and the just reward". In: IZA Discussion Paper.

McKelvey, Richard D and William Zavoina (1975). "A statistical model for the analysis of ordinal level dependent variables". In: Journal of Mathematical Sociology 4.1, pp. 103-120.

Milinski, Manfred and Bettina Rockenbach (2012). "On the interaction of the stick and the carrot in social dilemmas". In: Journal of Theoretical Biology 299, pp. 139-143.

Rand, David G, Anna Dreber, Tore Ellingsen, Drew Fudenberg, and Martin A Nowak (2009). "Positive interactions promote public cooperation". In: Science 325.5945 , pp. 1272-1275.

Rockenbach, Bettina and Manfred Milinski (2006). "The efficient interaction of indirect reciprocity and costly punishment". In: Nature 444.7120 , pp. 718 723. 
Sefton, Martin, Robert Shupp, and James M Walker (2007). "The effect of rewards and sanctions in provision of public goods". In: Economic Inquiry 45.4, pp. 671-690.

Sutter, Matthias, Stefan Haigner, and Martin G Kocher (2010). "Choosing the carrot or the stick? Endogenous institutional choice in social dilemma situations". In: The Review of Economic Studies 77.4, pp. 1540-1566. 


\section{A Appendix}

\section{A.1 Mann-Whitney $U$ test for population subgroups}

The tables below contain the Mann-Whitney U tests for different subgroups with populations of more than 1 player (see tables A1\&A2). Table A3 is an alternative representation of the data displayed on Fig.1 in the main body of the paper.

\begin{tabular}{|c|c|c||c|}
\hline Contibutions & $\mathrm{P}(\mathrm{PN})$ & $\mathrm{N}(\mathrm{PN})$ & $\mathrm{PN}$ \\
& 17.4 & 4.1 & 10.8 \\
\hline $\mathrm{P}(\mathrm{PR}) 15.0$ & $\mathrm{p}=0.0455$ & $\mathrm{p}=0.0043$ & \\
\hline $\mathrm{R}(\mathrm{PR}) 11.9$ & $\mathrm{p}=0.0455$ & $\mathrm{p}=0.0027$ & \\
\hline \hline PR 13.5 & & & $\mathrm{p}=0.504$ \\
\hline
\end{tabular}

Table A1: Average contribution per community, Mann-Whitney U test

\begin{tabular}{|c|c|c||c|}
\hline Points per period & $\mathrm{P}(\mathrm{PN})$ & $\mathrm{N}(\mathrm{PN})$ & $\mathrm{PN}$ \\
& 47.7 & 42.5 & 45.1 \\
\hline $\mathrm{P}(\mathrm{PR}) 44.7$ & $\mathrm{p}=0.32$ & $\mathrm{p}=0.15$ & \\
\hline $\mathrm{R}(\mathrm{PR}) 54.4$ & $\mathrm{p}=0.01$ & $\mathrm{p}=0.003$ & \\
\hline \hline $\mathrm{PR} 49.6$ & & & $\mathrm{p}=0.03$ \\
\hline
\end{tabular}

Table A2: Average points per period per community, Mann-Whitney U test

\begin{tabular}{|c|c|c|c|c|c|c|c|c|c|}
\hline \multirow[t]{2}{*}{ Periods } & \multicolumn{4}{|c|}{ Contribution } & \multicolumn{3}{|c|}{ Distributed points } & \multicolumn{2}{|c|}{$\begin{array}{c}\% \text { of Subjects } \\
\text { in the Punishment } \\
\text { Group }\end{array}$} \\
\hline & $\mathrm{P}(\mathrm{PN})$ & $\mathrm{N}(\mathrm{PN})$ & $\mathrm{P}(\mathrm{PR})$ & $\mathrm{R}(\mathrm{PR})$ & $\mathrm{P}(\mathrm{PN})$ & $\mathrm{P}(\mathrm{PR})$ & $\mathrm{R}(\mathrm{PR})$ & $\mathrm{PN}$ & $\mathrm{PR}$ \\
\hline $1-3$ & 14.9 & 6.2 & 10.6 & 12.2 & 2.8 & 1.2 & 6.9 & 38.0 & 15.5 \\
\hline 4-6 & 18.3 & 3.1 & 13.7 & 15.1 & 1.1 & 0.5 & 5.9 & 48.6 & 9.5 \\
\hline 7-9 & 19.1 & 0.9 & 13.6 & 14.2 & 1.0 & 1.3 & 4.0 & 62.0 & 8.9 \\
\hline $10-12$ & 19.0 & 0.5 & 15.1 & 12.6 & 1.2 & 0.2 & 3.1 & 70.8 & 7.1 \\
\hline $13-15$ & 19.5 & 0.3 & 17.3 & 13.1 & 0.5 & 0.5 & 4.0 & 72.2 & 8.7 \\
\hline $16-18$ & 19.3 & 0.7 & 20.0 & 12.5 & 0.2 & 0 & 3.4 & 76.4 & 9.5 \\
\hline $19-21$ & 18.3 & 3.0 & 19.7 & 10.4 & 0.2 & 0.1 & 2.1 & 82.4 & 17.1 \\
\hline $22-24$ & 18.4 & 3.7 & 17.8 & 9.5 & 0.3 & 1.2 & 1.9 & 82.9 & 24.6 \\
\hline $25-27$ & 18.6 & 3.1 & 19.2 & 10.6 & 0.3 & 0.6 & 2.3 & 83.3 & 31.7 \\
\hline 28-30 & 18.8 & 2.9 & 19.9 & 8.0 & 0.4 & 0.1 & 1.4 & 85.2 & 38.9 \\
\hline
\end{tabular}

Table A3: Table representation of Figure 1 
Table A4: Marginal Effects of the Determinants for Migration

\begin{tabular}{|c|c|c|c|c|}
\hline Switched in $t+1$ & $\begin{array}{c}(1) \\
\mathrm{N} \text { to } \mathrm{P}\end{array}$ & $\begin{array}{c}(2) \\
\mathrm{P} \text { to } \mathrm{N}\end{array}$ & $\begin{array}{c}(3) \\
\mathrm{R} \text { to } \mathrm{P}\end{array}$ & $\begin{array}{c}(4) \\
\mathrm{P} \text { to } \mathrm{R}\end{array}$ \\
\hline Received Points & & $\begin{array}{c}0.00781^{* * *} \\
(0.00205)\end{array}$ & $\begin{array}{r}-0.000441 \\
(0.00169)\end{array}$ & $\begin{array}{r}-0.00267 \\
(0.0165)\end{array}$ \\
\hline DV:Antisocial Behavior & & $\begin{array}{l}0.00400 \\
(0.0190)\end{array}$ & $\begin{array}{c}0.0828^{* * *} \\
(0.0243)\end{array}$ & $\begin{array}{r}0.272^{* * *} \\
(0.0235)\end{array}$ \\
\hline \multirow[t]{2}{*}{$\begin{array}{l}\text { Minimum of Others' } \\
\text { Contribution in Own Community }\end{array}$} & $-0.0108^{*}$ & $-0.00214^{* *}$ & $-0.00239^{* * *}$ & -0.00490 \\
\hline & $(0.00581)$ & $(0.000960)$ & $(0.000908)$ & $(0.00548)$ \\
\hline \multirow[t]{2}{*}{$\begin{array}{l}\text { Maximum of Others' } \\
\text { Contribution in Own Community }\end{array}$} & -0.00574 & $-0.00282^{* * *}$ & $-0.00579^{* * *}$ & -0.0154 \\
\hline & $(0.00551)$ & $(0.000507)$ & $(0.00147)$ & $(0.0137)$ \\
\hline \multirow{2}{*}{$\begin{array}{l}\text { Average Contribution } \\
\text { in Other Community }\end{array}$} & $0.0122^{* * *}$ & $0.00536^{* * *}$ & 0.000867 & $0.0277^{* * *}$ \\
\hline & $(0.00446)$ & $(0.000911)$ & $(0.00128)$ & $(0.00666)$ \\
\hline \multirow[t]{2}{*}{$\begin{array}{l}\text { Difference of Income } \\
\text { within Community }\end{array}$} & $-0.630^{* * *}$ & 0.000316 & $-0.0404^{* *}$ & -0.0489 \\
\hline & $(0.181)$ & $(0.0172)$ & $(0.0195)$ & $(0.173)$ \\
\hline \multirow{2}{*}{$\begin{array}{l}\text { Difference of Income } \\
\text { between Communities }\end{array}$} & $-0.00569 * * *$ & 0.000393 & $-0.000943^{* *}$ & -0.00237 \\
\hline & $(0.00168)$ & $(0.000379)$ & $(0.000417)$ & $(0.00304)$ \\
\hline \multirow[t]{2}{*}{$\begin{array}{l}\% \text { of Free-Riders } \\
\text { in Community }\end{array}$} & -0.000980 & -0.000497 & $0.000983^{* *}$ & $0.00364^{*}$ \\
\hline & $(0.000777)$ & $(0.000507)$ & $(0.000468)$ & $(0.00203)$ \\
\hline Size of the Community & $\begin{array}{c}0.00851 \\
(0.00974)\end{array}$ & $\begin{array}{c}-0.00489^{* * *} \\
(0.00181)\end{array}$ & $\begin{array}{l}-0.00256 \\
(0.00628)\end{array}$ & $\begin{array}{c}-0.00944 \\
(0.0103)\end{array}$ \\
\hline Observations & 609 & 1,440 & 2,039 & 346 \\
\hline $\mathrm{R}^{2}$ & 0.44 & 0.56 & 0.35 & 0.62 \\
\hline
\end{tabular}

Note: Random-effects Probit estimation; standard errors in parentheses, $* * * \mathrm{p}<0.01, * * \mathrm{p}<0.05, * \mathrm{p}<0.1$;

$\mathrm{R}^{2}$ is calculated for the respective panel probit specification and is mentioned here for completeness. $\mathrm{R}^{2}$ is calculated after McKelvey and Zavoina (1975).

Difference of income within community $=\ln$ (Actual payoff/ Equal payoff), negative sign indicates increase in likelihood of migration to $\mathrm{P}$ in the next period. 


\section{A.2 Additional Figures}
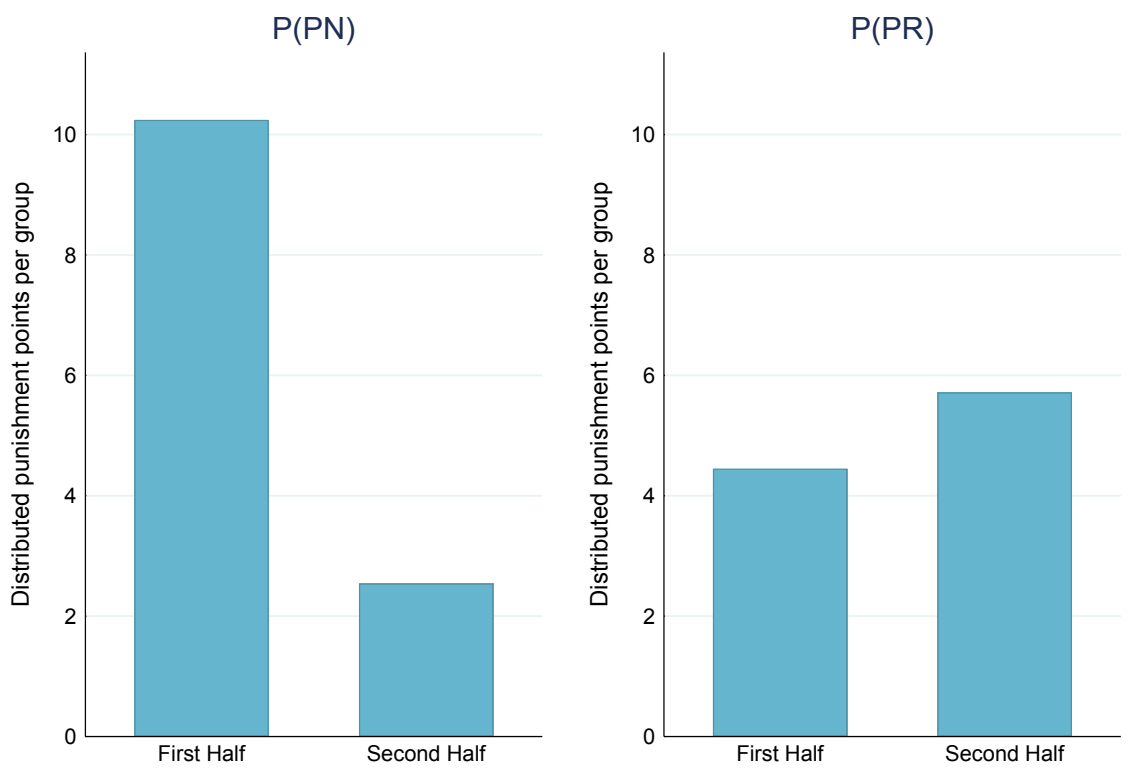

Figure A1: Average use of punishment points per group in $\mathrm{P}(\mathrm{PN})$ and $\mathrm{P}(\mathrm{PR})$ in two halves of the experiment. 

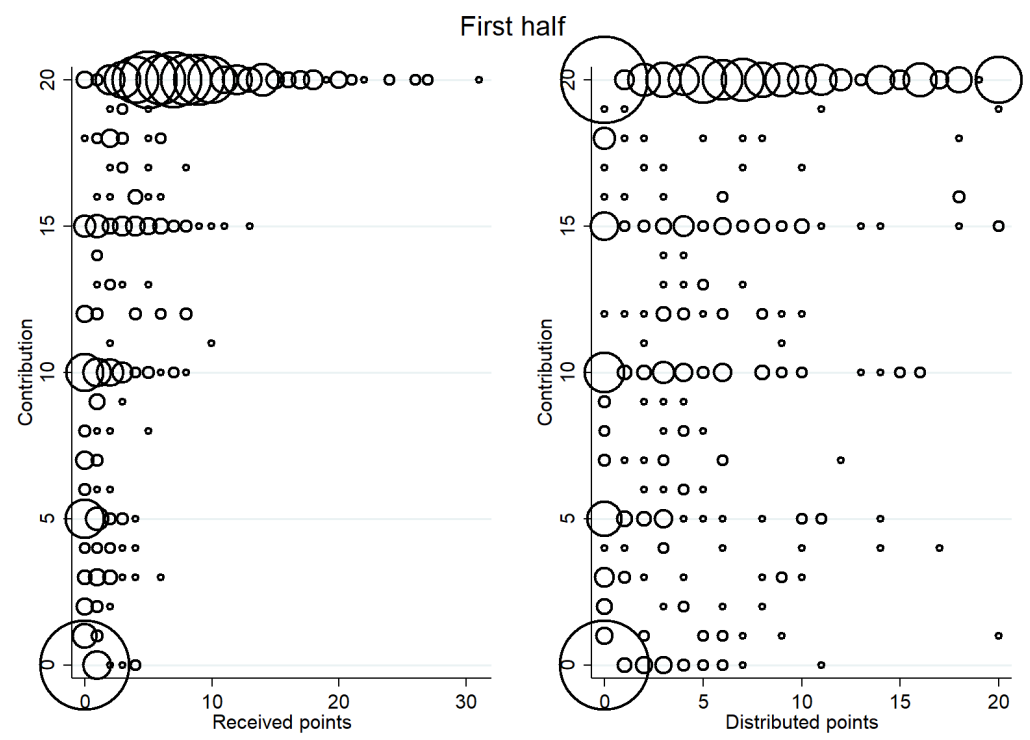

Figure A2: $\quad R(P R)$ : received and distributed points depending on own contribution in the $1^{\text {st }}$ half of the game.

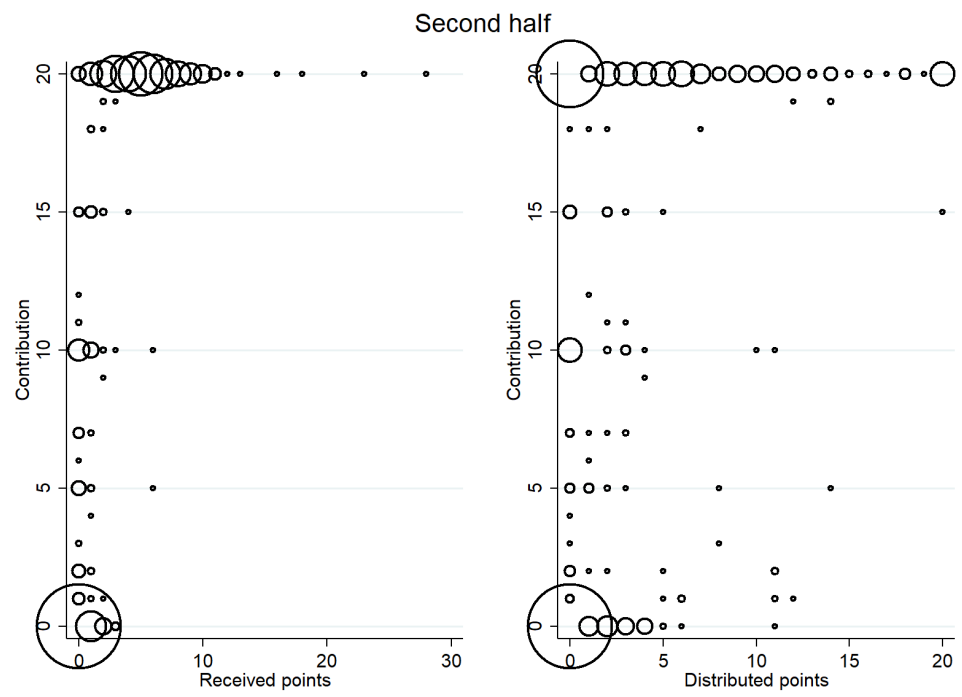

Figure A3: $\mathrm{R}(\mathrm{PR})$ : received and distributed points depending on own contribution for the $2^{\text {nd }}$ half of the game.

Comparing Figures $\mathrm{A} 2$ and $\mathrm{A} 3$, we see that in the $\mathrm{R}(\mathrm{PR})$ in the first half of the game a share of rewards is awarded by people with medium or low contributions (lower part of the right panel in Fig. A2). These reward points predominantly go to full contributors, with clusters of positive reward points received on all levels of contributions (left panel). The test confirms that in the second half, significantly fewer medium- or low-contributors (i.e., contributions of 10 or less) use the reward system than in the first half $(\mathrm{p}=0.003$, two-sided test of proportions). Thus, the rewards are predominantly handed out by full-contributors (right panel in Fig. A3). 


\section{B Instructions: PR treatment ${ }^{9}$}

\section{Instructions for the experiment}

\section{General instructions}

At the beginning of the experiment you will be randomly divided into 2 groups of 12 participants each. During the experiment, you will be interacting only with the members of the same subgroup.

At the beginning of the experiment each participant receives a starting endowment of 1000 points. Before the beginning of the experiment there are 5 questions of understanding.

\section{Procedure}

Experiment consists of $\mathbf{3 0}$ rounds. Each round consists of 2 stages. The first stage includes the choice of the group and decision about the contribution into the common project. In the second stage participants can affect the outcome of other members of his/her group.

\section{First Stage}

\section{(i) Choice of the group}

In the first stage, each participant can decide, which group to join.

There are two different groups:

\begin{tabular}{|l|}
\hline Affecting the income of the other members of the group \\
A: Through assignment of negative points \\
B: Through assignment of positive points
\end{tabular}

\section{(ii) Contribution to the common project}

Each round in the beginning of the first stage each member of the group receives an endowment of 20 Points.

You decide how many of the 20 Points you want to contribute to the common project. The remaining part of the endowment, you keep to yourself.

\section{Calculation of your income from the first stage}

Your income from the first stage consist of two parts:

- Points which you kept to yourself $=$ Endowment - your contribution to the common project

- Your profit from the common project $=1.6 \times$ sum of all the contribution to the project of all the community members/ number of members in the community

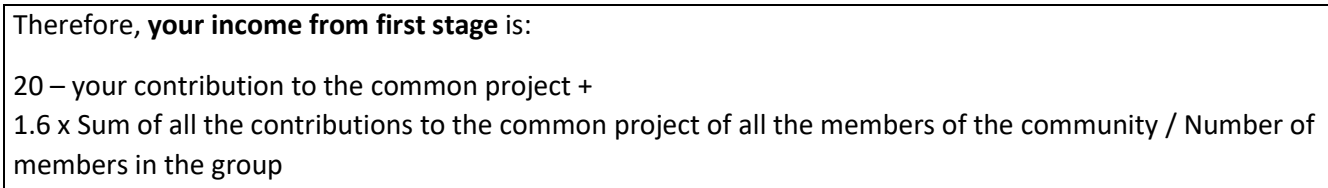

The profit from the common project will be calculated according this formula individually for each member of the community. Please note: Each member of the community receives the same profit

\footnotetext{
${ }^{9}$ Original instructions in German can be obtained from the authors upon request.
} 
from the common project. It means that each member of the group profits from all the contributions to the project.

\section{Second Stage}

\section{Assignment of Points}

In the second stage, you see how much each member of the group contributed to the common project. (Please note: The sequence of players is reshuffled every round. Therefore, it is not possible to identify a group member over different rounds by their position in the displayed list.)

By assigning points, you can increase, decrease or leave the income of the other group members unchanged.

In the second stage of every round each participant receives $\mathbf{2 0}$ additional points. You decide how many of these 20 points you want to assign to the other group members. You keep the remaining points to yourself. To check how many points you have assigned, press the Calculate Points button on your screen.

- Each positive point, which you assign to a group member, increases the income of this group member by 3 Points.

- Each negative point, which you assign to a group member, reduces the income of this group member by 3 points.

- If you assign $\mathbf{0}$ points to a group member, the income of this group member remains unchanged.

\section{Calculation of your income from the second stage}

Your income from the second stage consist of three parts:

- Points kept to yourself $=20$ - sum of the points you assigned to the other group members.

- plus 3 times the number of positive points you received from the other group members

or

- minus 3 times the number of negative points that you received from other group members.

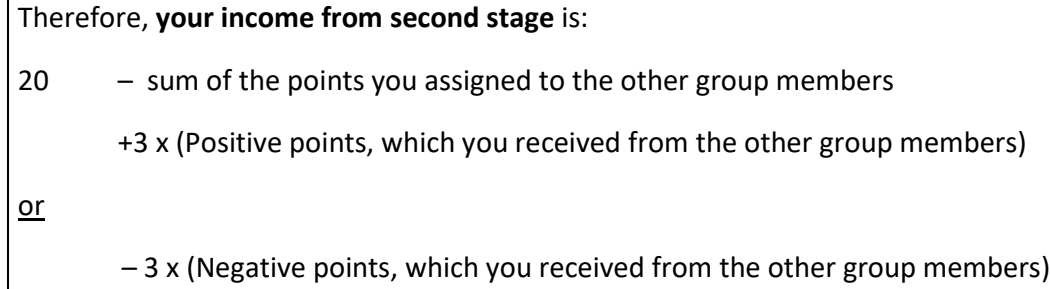




\section{Calculation of your round income}

Your round income is calculated as follows:

$\begin{aligned} & \text { Your income from } \\ & \text { the first stage }\end{aligned}$
$\begin{aligned} & =20-\text { your contribution to the common project }+ \\ & 1.6 \times \text { Sum of all the contributions to the common project of all the members of the } \\ & \text { community / Number of members in the group }\end{aligned}$
$+\begin{array}{r}\text { Your income from } \\ \text { the second stage }\end{array} \quad 20-$ sum of the points you assigned to the other group members
$+3 \times$ (Positive points, which you received from the other group members)
$-3 \times$ (Negative points, which you received from the other group members)

$=$ Your round income

\section{Special case: single group member}

Should you be the only member in your group, you receive 20 points in the first stage and 20 points in the second stage, that is your round income is $\mathbf{4 0}$. You can act neither during the first nor during the second stage.

\section{Information at the end of the round}

At the end of the round, you will receive a detailed overview of the results from all groups. For each member of the group, you will see: their contribution to the project, their income from the first stage, points they assigned (if possible), points they received (if possible), their income from the second stage and their round income.

\section{History}

Starting in round two, before the start of a new round you will see an overview of the average results (as above) of all previous rounds.

\section{$\underline{\text { Total income }}$}

The total income from the experiment consists of the starting capital of 1000 points plus the sum of the round incomes of the 30 rounds.

At the end of the experiment, your total income will be paid at an exchange rate of $1 €$ per 100 points.

\section{Please note:}

No communication is allowed during the entire experiment. If you have a question, please raise your hand. All decisions are anonymous, meaning that none of the other participants or the experimenters will know the identity of the person who has made a particular decision. The payout is also anonymous: no participant will know how much other participants have earned.

Good Luck! 